\title{
Bibliometric analysis of international cooperation in biomass energy research
}

\author{
Xiaorong He and Dejian Yu*
}

It is well known that biomass energy has excellent environmental and economic benefits. The increasing international cooperation in the field of biomass energy has promoted the rapid coordinated development of global biomass energy research and industry. This article analyses academic papers in this field collected by SSCI or SCI from 2007 to 2016, uses bibliometrics for quantitative statistics and data mining, and VOSviewer software to generate international cooperation network maps. It also provides in-depth analysis and comprehensive comparison of changes in international cooperation in biomass energy research in major countries around the world, and reveals the context and direction of development in the global biomass energy field. The results of this study can provide scientific basis and support for the development of other related research work.

Keywords: Biomass energy, bibliometrics, data mining, international collaboration.

BIOMASS energy plays an important role in responding to global climate change, energy supply and demand contradiction, and protecting the ecological environment ${ }^{1}$. It is the world's fourth largest energy source after oil, coal and natural gas, and has become an important force in the international energy transformation. At present, many countries not only formulate policies and measures to promote the development of biomass energy, but also set development goals and plans ${ }^{2}$. The development and utilization of biomass energy has attracted extensive attention from governments and scientists in various countries.

International scientific and technological cooperation has become an important model for the development of scientific research. Making full use of the world's advanced scientific and technological resources to develop and strengthen international cooperation has become an important part of scientific research, and has promoted the progress and innovation of science and technology (S\&T). Energy and the environment are the main concerns of countries around the world. Research on biomass energy is the hot topic around the world. With the gradual deepening of research on biomass energy, breakthrough achievements have been made in the field. However, it is necessary to point out that international cooperation plays a key role that cannot be ignored.

Bibliometrics refers to the use of mathematical and statistical methods to quantitatively analyse the crossscience of all knowledge carriers ${ }^{3-6}$. It is a comprehensive

\footnotetext{
Xiaorong He is in the School of Information Engineering; Dejian $\mathrm{Yu}$ is in the School of Business, Nanjing Audit University, Nanjing, Jiangsu 211815, China.

*For correspondence. (e-mail: yudejian62@126.com)
}

knowledge system that integrates mathematics, statistics and philology as a whole, and focuses on quantification ${ }^{7-9}$. Bibliometric methods are widely used in many areas, including medical science ${ }^{10}$, environmental science $^{11}$, management ${ }^{12}$, business ${ }^{13}$ and computer science ${ }^{14}$.

Bibliometrics is also common in research through international cooperation. Some scholars analysed different issues, including the structure of international cooperation networks, cooperation models, cooperation intensity and the trend of their changes. Glänzel et al. ${ }^{15}$ performed a bibliometric analysis of scientific cooperation of the European Union countries with other highly industrialized countries and less advanced countries. Based on the bibliometric analysis of the top journals in the energy area, Duan ${ }^{16}$ found that most critical partner countries for China are USA, some European countries and Japan. With more than 100,000 papers as research samples, Li and $\mathrm{Zhao}^{17}$ studied the issues of international cooperation in the field of environmental assessment. By using network centralities, they effectively identified the core countries in the international cooperation network in this field. Merigó et al. ${ }^{18}$ studied the structure, patterns, and maps of international cooperation networks in the field of innovation. De Paulo and Porto ${ }^{19}$ examined international cooperation in the field of solar energy technologies. Bibliometric and social network analysis methods were used to explore the national and international partnerships. They indicated that international cooperation in the field of solar energy technology is common in some developed countries like the Netherlands, Germany and United Kingdom. But so far bibliometrics has not been used in international cooperation studies in the field of biomass energy, which is the focus of the present study. It deals with two aspects of the basic situation of international 
cooperation and international cooperation network in the field of biomass energy.

\section{Data and methods}

ISI Web of Science is the largest and most comprehensive academic information resource in the world ${ }^{20,21}$. It integrates Science Citation Index Expanded (SCIE), Social Science Citation Index (SSCI), Arts \& Humanities Citation Index (A\&HCI), and the original conference proceedings database on the Web of Knowledge platform. Based on the research scope of biomass energy, this study adopts the topic retrieval method to search the biomass energy research literature from 2007 to 2016 with 'biomass OR biofuel OR biodiesel OR bioethanol OR biomass power or biogas, ${ }^{22}$. The retrieval time is 12 April 2017. The literature types are limited to research articles and review, and a total of 172,029 original article records were obtained.

Essential Science Indicators (ESI) is a literature review analysis tool introduced by ISI in 2001 (refs 22-24). This is an econometric analysis database established based on more than 10 million document records collected by SCI and SSCI from over 11,000 academic journals worldwide. Through this database, users can understand the leading countries, journals, scientists, papers and research institutions in each field of research, and identify important trends and directions in various fields ${ }^{25-27}$. The present study collected all ESI papers in the field of biomass energy to examine international cooperation issues in the field. On 12 April 2017, 3185 ESI papers in the field of biomass energy were retrieved. The main purpose of this study to reveal the international cooperation in the field of biomass energy. VOSviewer is a software tool for constructing and visualizing bibliometric networks ${ }^{28-30}$. This was used for mapping the international cooperation network in the field of biomass energy.

\section{Results}

With the globalization of S\&T, international cooperation has become an indispensable and important component in this field. As an important measure of optimal allocation of resources in national S\&T development strategy, international cooperation plays an important supporting role in enhancing national independent innovation capability. Using the personalized data mining method, this study systematically analyses the papers through international cooperation in the field of biomass energy, reveals the modes and characteristics of international cooperation in the field, and describes the status and role of the countries in the cooperative network.

Table 1 lists the number of papers through independent research and international cooperation among the top 20 countries during 2007-2016 in the field of biomass energy.
With the rapid development of this field, the absolute number of publications of various countries in Table 1, whether through independent research or international cooperation, is growing. For example, the number of papers through international cooperation in USA increased from 9775 during 2007-2011 to 13,811 during 2012-2016, while the number of independent research papers increased from 4408 to 9591 in the same period.

According to the share of international cooperation and independent research, the former has become the main research model of Germany and the UK during 2012-2016. The number of papers through international cooperation of these two countries far exceeds the results of independent research publications. In this period, in addition to Germany and the UK, countries with a higher proportion of international cooperation include Canada, France, Australia, the Netherlands, Sweden, Denmark and Finland.

Comparing the changes in the share of international cooperation and independent research between the two periods, it can be found that the vast majority of countries have increased their share of international cooperation. This indicates that most countries have given international cooperation research more attention. However, the international cooperation share of China and South Korea has shown a downward trend. For example, China's international cooperation share has dropped from $69.00 \%$ to $30.41 \%$, and South Korea's share dropped from $37.93 \%$ to $34.71 \%$.

Table 2 provides details on international cooperation and independent research of ESI publications in the field of biomass energy. The conclusions are similar to those in Table 1. But it is clear that, for the vast majority of countries, the international cooperation rate shown in Table 2 is significantly higher than that in Table 1 . This shows that international cooperation is more conducive to yielding high-impact research results in the field of biomass energy.

At present, international scientific and technological cooperation has gradually become an inevitable choice for scientific research ${ }^{31}$. It is of great significance to analyse the characteristics of international cooperation between different countries in the field of biomass energy. Table 3 provides the details of the five countries with the most cooperation among the top 20 countries (according to the international cooperation publication number).

During the period 2007-2016, the country with the largest number of papers co-authored with USA was China, with a total of 3639 publications. This was followed by Canada, the UK, Germany, and Australia. As can be seen from Table 3, USA is the world's major partner in international cooperation in the field of biomass energy. This indicates that these countries played an important role in building a strong international cooperation network. Table 4 provides information on the most popular partner of ESI publications in the field of biomass energy. We studied the co-authorship of ESI publications 


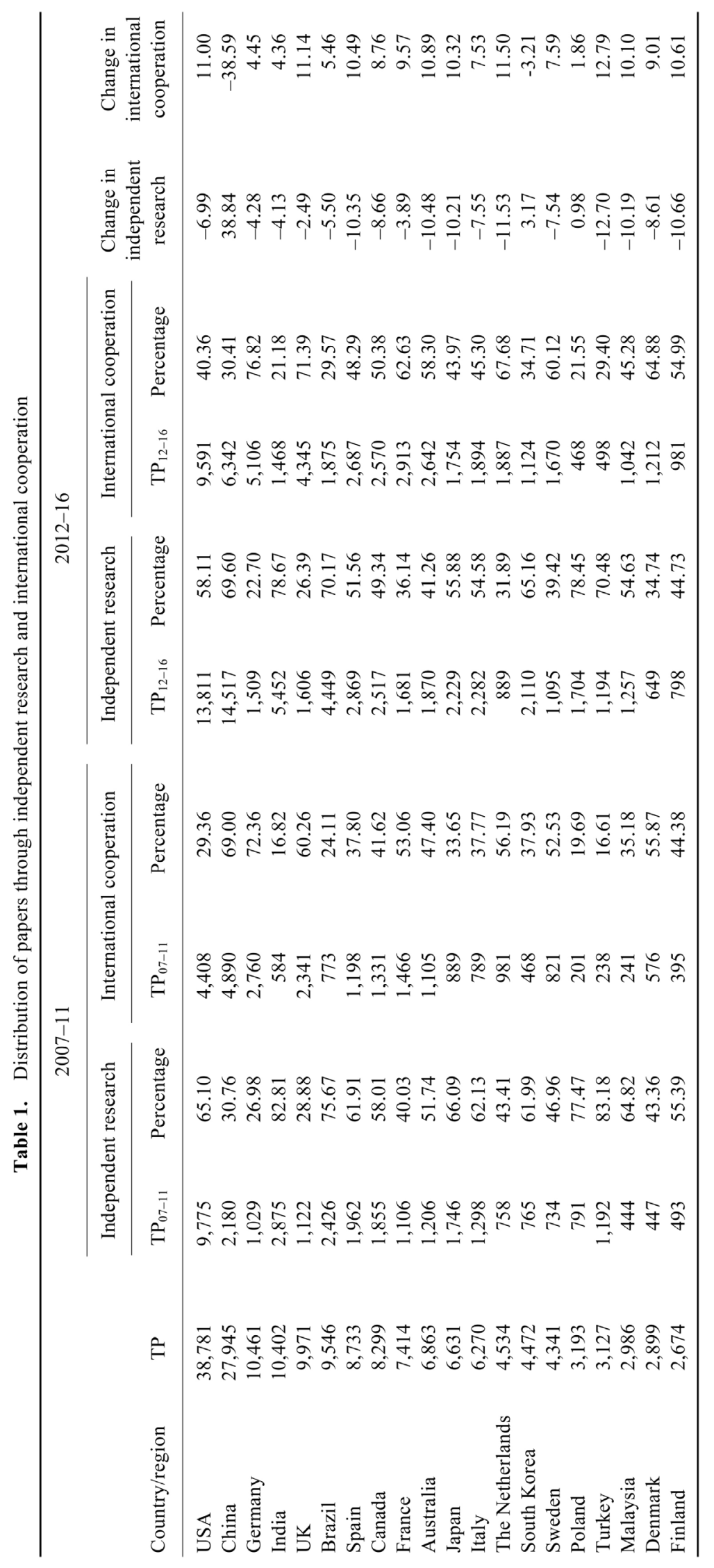




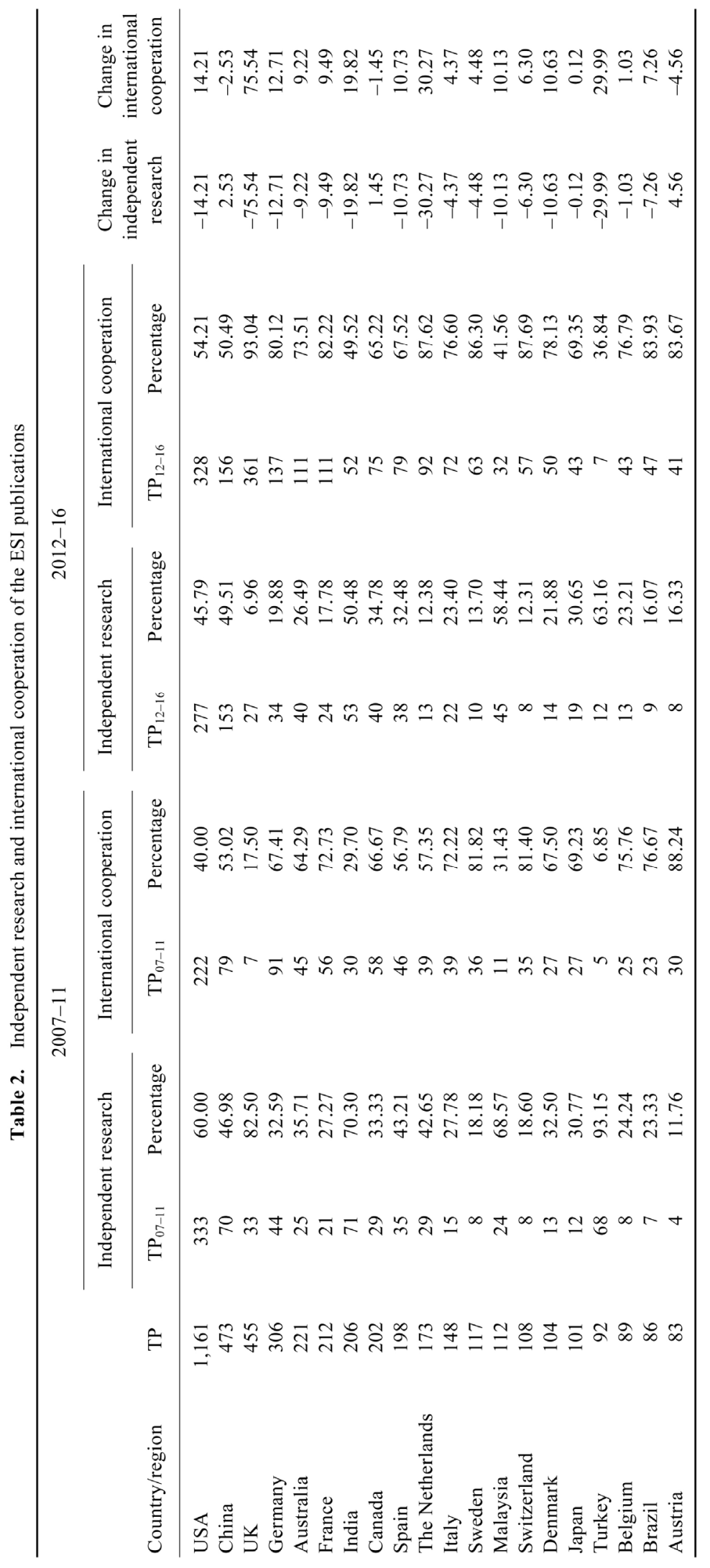




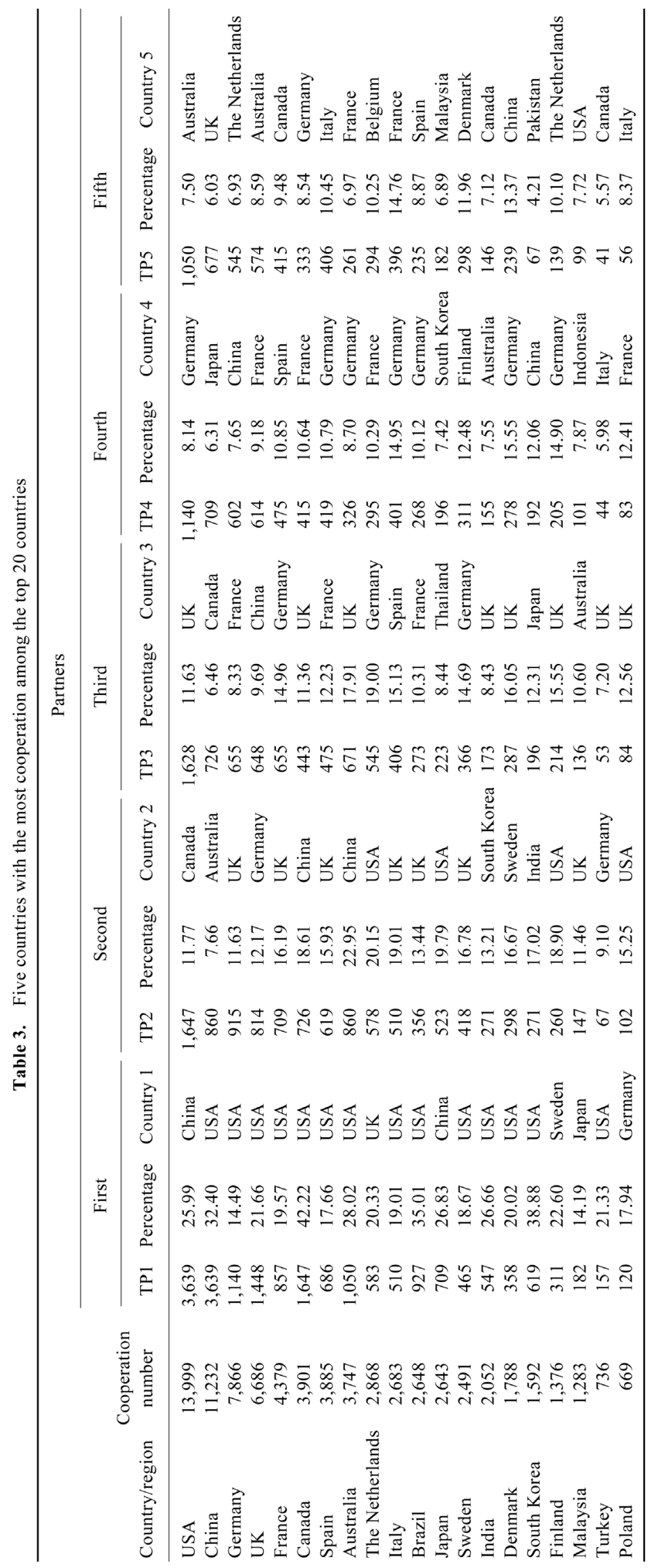




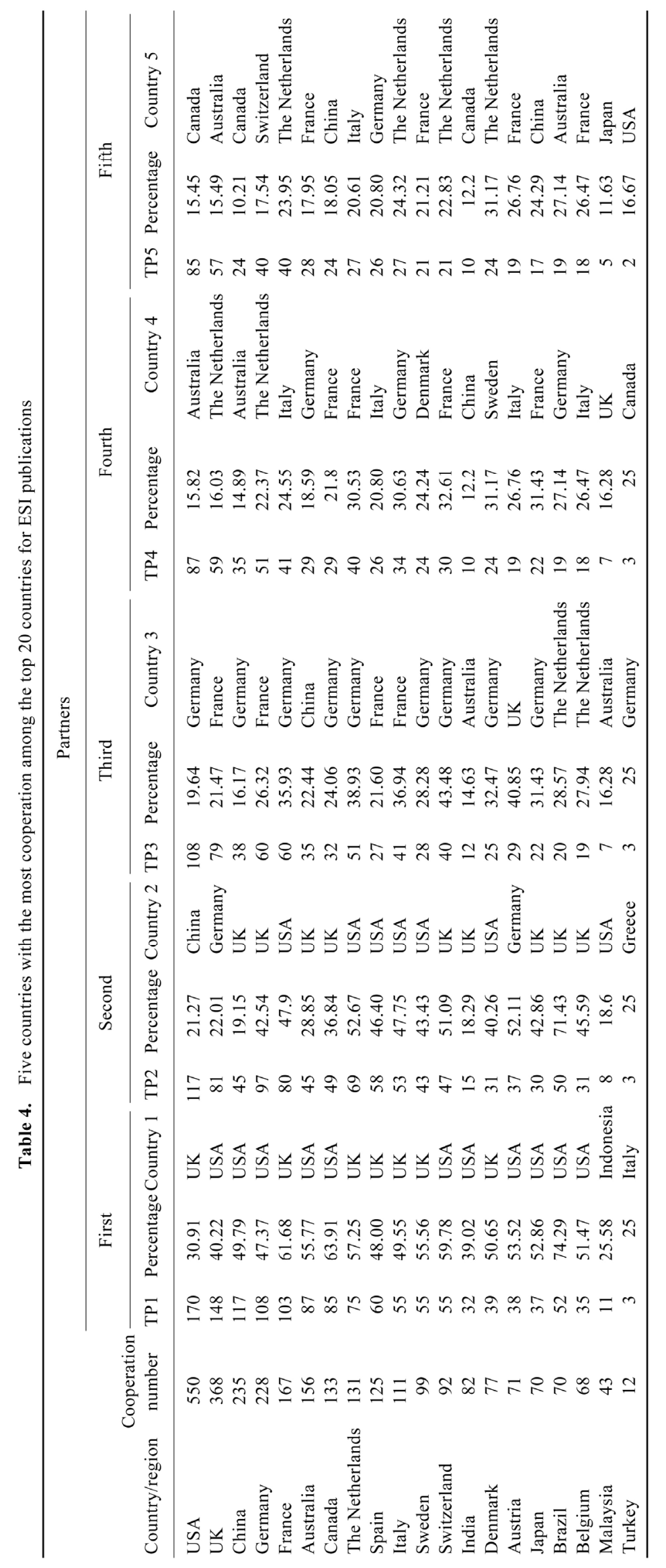




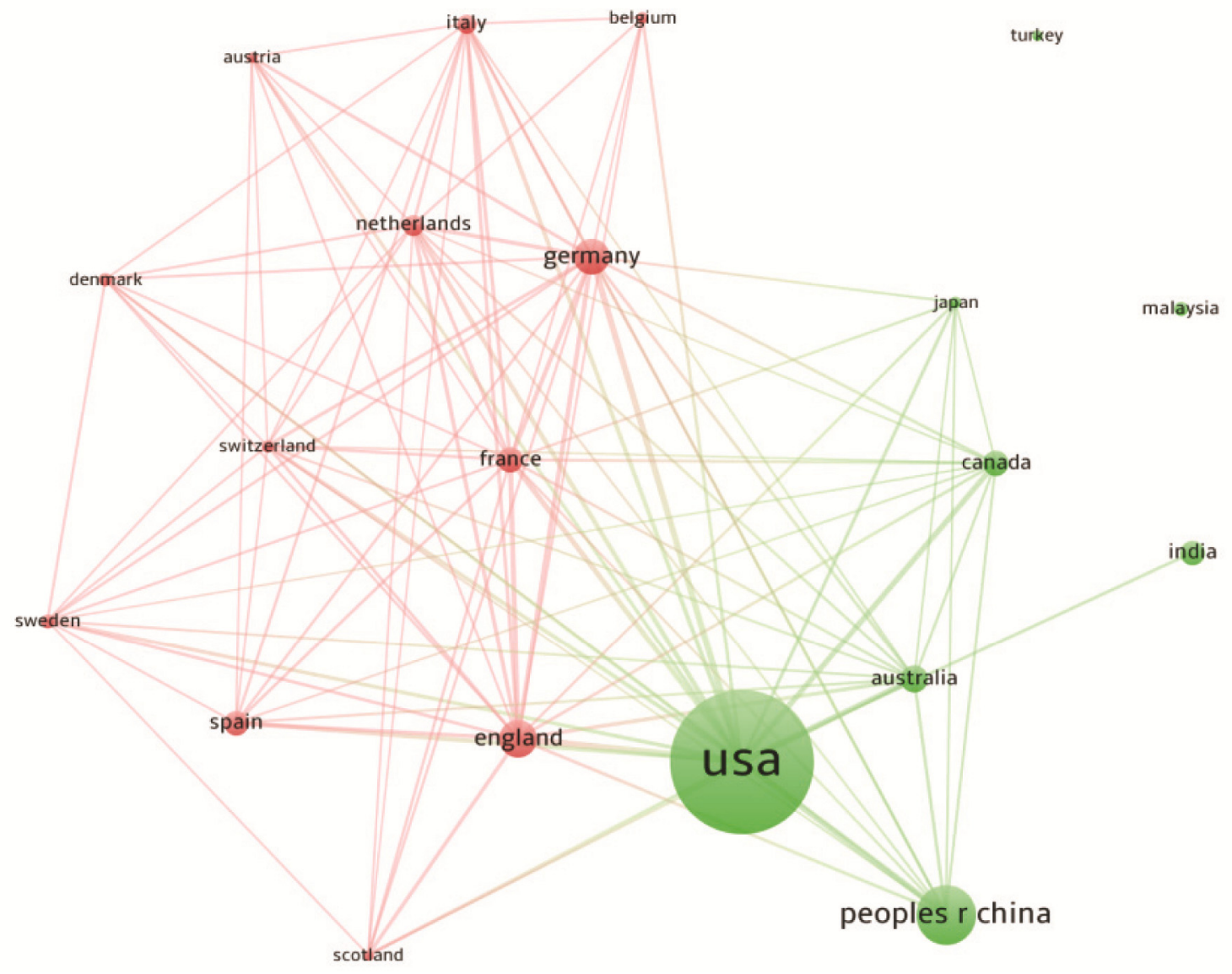

Figure 1. Co-authorship of the top 20 countries.

in the field of biomass energy. Figure 1 presents the coauthorship of the top 20 countries.

\section{Conclusion}

Through a literature review of relevant international biomass energy research papers, the international cooperation from 2007 to 2016 has been revealed from a quantitative and qualitative perspective. The analysis results are as follows:

(1) In the field of biomass energy, the number of research papers has grown rapidly, indicating that researchers are paying more attention to this field. (2) The main countries for biomass energy research are USA, China, Germany, India and the UK. Among them, USA ranks first in the field in absolute research, and China ranks second, but China's research literature in this field has grown the fastest, indicating that it has considerable potential in research in this field. (3) The country with the largest number of papers co-authored with USA is China, followed by Canada, the UK, Germany and Australia. USA is the world's major partners in international cooperation, and it has become the leading force in inter- national cooperation in the field of biomass energy. (4) The vast majority of countries have increased their share of international cooperation. International cooperation is more conducive to yielding high-impact research results in the field of biomass energy.

In summary, international biomass energy research has developed rapidly and international cooperation has become an important method for research in this field. Actively attracting international innovation forces and resources, and strengthening cooperation with the developed countries can further enhance the academic influence of research in the field of biomass energy.

1. Herbert, G. J. and Krishnan, A. U., Quantifying environmental performance of biomass energy. Renew. Sust. Energ. Rev., 2016, 59, 292-308.

2. Yu, D. J. and Xu, C., Mapping research on carbon emissions trading: a co-citation analysis. Renew. Sust. Energ. Rev., 2017, 74, 1314-1322.

3. Elango, B. and Ho, Y. S., A bibliometric analysis of highly cited papers from India in Science Citation Index Expanded. Curr. Sci., 2017, 112(8), 1653-1658.

4. Merigó, J. M. and Yang, J. B., A bibliometric analysis of operations research and management science. Omega, 2017, 73, 37-48. 
5. Yu, D. J., Xu, Z. S. and Wang, W. R., Bibliometric analysis of fuzzy theory research in China: A 30-year perspective. Knowl.Based Syst., 2018, 141, 188-199.

6. Yu, D. J., Xu, Z. S. and Fujita, H., Bibliometric analysis on the evolution of applied intelligence. Appl. Intell., 2019, 49(2), 449462 .

7. Laengle, S. et al., Forty years of the European Journal of Operational Research: a bibliometric overview. Eur. J. Oper. Res., 2017, 262(3), 803-816.

8. Yu, D. J., Wang, W. R., Zhang, S., Zhang, W. Y. and Liu, R. Y., A multiple-link, mutually reinforced journal-ranking model to measure the prestige of journals. Scientometrics, 2017, 111(1), 521-542.

9. Wang, P., Zhu, F., Song, H. and Hou, J., A bibliometric profile of Current Science between 1961 and 2015. Curr. Sci., 2017, 113(3), 386-392.

10. Takahashi, R. and Kajikawa, Y., Computer-aided diagnosis: a survey with bibliometric analysis. Int. J. Med. Informat., 2017, 101, 58-67.

11. Zhang, S., Mao, G., Crittenden, J., Liu, X. and Du, H., Groundwater remediation from the past to the future: a bibliometric analysis. Water Res., 2017, 119, 114-125.

12. Oraee, M., Hosseini, M. R., Papadonikolaki, E., Palliyaguru, R. and Arashpour, M., Collaboration in BIM-based construction networks: a bibliometric-qualitative literature review. Int. J. Project Manage., 2017, 35(7), 1288-1301.

13. Sarin, S., Haon, C. and Belkhouja, M., A bibliometric analysis of the knowledge exchange patterns between major technology and innovation management journals (1999-2013). J. Prod. Innov. Manage., 2018, 35(1), 2-8.

14. Yu, D. J., Xu, Z. S. and Wang, X. Z., Bibliometric analysis of support vector machines research trend: a case study in China. Int. J. Machine Learn. Cyber., 2019, in press, doi:10.1007/s13042019-01028-y.

15. Glänzel, W., Schubert, A. and Czerwon, H. J., A bibliometric analysis of international scientific cooperation of the European Union (1985-1995). Scientometrics, 1999, 45(2), 185-202.

16. Duan, L., Analysis of the relationship between international cooperation and scientific publications in energy R\&D in China. Appl. Energ., 2011, 88(12), 4229-4238.

17. Li, W. and Zhao, Y., Bibliometric analysis of global environmental assessment research in a 20 -year period. Environ. Impact Assess. Rev., 2015, 50, 158-166.

18. Merigó, J. M., Cancino, C. A., Coronado, F. and Urbano, D., Academic research in innovation: a country analysis. Scientometrics, 2016, 108(2), 559-593.
19. De Paulo, A. F. and Porto, G. S., Solar energy technologies and open innovation: a study based on bibliometric and social network analysis. Energ. Policy, 2017, 108, 228-238.

20. He, X. R., Wu, Y. Y., Yu, D. J. and Merigó, J. M., Exploring the ordered weighted averaging operator knowledge domain: a bibliometric analysis. Int. J. Intell. Syst., 2017, 32(11), 1151-1166.

21. Yu, D. J., Xu, Z. S, Pedrycz, W. and Wang, W., Information Sciences 1968-2016: a retrospective analysis with text mining and bibliometric. Inform. Sci., 2017, 418, 619-634.

22. Yu, D. J. and Meng, S., An overview of biomass energy research with bibliometric indicators. Energ. Environ., 2018, 29(4), 576590 .

23. Weingart, P., Impact of bibliometrics upon the science system: inadvertent consequences? Scientometrics, 2005, 62(1), 117-131.

24. Fu, H. Z., Chuang, K. Y., Wang, M. H. and Ho, Y. S., Characteristics of research in China assessed with Essential Science Indicators. Scientometrics, 2011, 88(3), 841-862.

25. Cova, T. F., Pais, A. A. and Formosinho, S. J., Iberian universities: a characterisation from ESI rankings. Scientometrics, 2013, 94(3), 1239-1251.

26. Merigó, J. M., Pedrycz, W., Weber, R. and de la Sotta, C., Fifty years of Information Sciences: a bibliometric overview. Inform. Sci., 2018, 432, 245-268.

27. Yu, D. J., Xu, Z. S. and Šaparauskas, J., The evolution of Technological and Economic Development of Economy: a bibliometric analysis. Technol. Econ. Dev. Econ., 2019, 25(3), 369-385.

28. Van Eck, N. J. and Waltman, L., Software survey: VOSviewer, a computer program for bibliometric mapping. Scientometrics, 2010, 84(2), 523-538.

29. Van Eck, N. J. and Waltman, L., Citation-based clustering of publications using CitNetExplorer and VOSviewer. Scientometrics, 2017, 111(2), 1053-1070.

30. Wong, D., VOSviewer. Tech. Serv. Q., 2018, 35(2), 219-220.

31. Cheng, Y., Johansen, J. and Hu, H., Exploring the interaction between R\&D and production in their globalisation. Int. J. Oper. Prod. Manage., 2015, 35(5), 782-816.

ACKNOWLEDGEMENTS. This study was supported by the Ministry of Education of Humanities and Social Science Project (No. 19YJC630208) and the Qinglan Project of Jiangsu Province (2019), and the Natural Science Foundation of Jiangsu Province (BK20180821), China.

Received 1 May 2018; revised accepted 1 August 2019

doi: $10.18520 / \mathrm{cs} / \mathrm{v} 117 / \mathrm{i} 11 / 1785-1792$ 